\title{
DESKRIPSI SMA/SMK DI KABUPATEN MINAHASA TENGGARA BERDASARKAN INDIKATOR STANDAR NASIONAL PENDIDIKAN BERBASIS EVALUASI DIRI SEKOLAH (STANDAR SARANA DAN PRASARANA, STANDAR PENGELOLAAN, STANDAR PEMBIAYAAN PENDIDIKAN DAN STANDAR PENILAIAN PENDIDIKAN)
}

\author{
Patrix Rembang ${ }^{1)}$, Djoni Hatidja ${ }^{\left.1^{*}\right)}$, Hanny Komalig ${ }^{1)}$ \\ 1)Program Studi Matematika, FMIPA, UNSRAT Jl. Kampus Unsrat, Manado 95115 \\ *) Coresponding author: dhatidja@gmail.com \\ Email: patrixrembang10@gmail.com; hanny@gmail.com
}

\begin{abstract}
ABSTRAK
Standar Nasional Pendidikan merupakan sistem pendidikan yang diterapkan di seluruh wilayah hukum Negara Kesatuan Republik Indonesia. Tujuan dari penelitian ini yaitu Mendeskripsikan SMA/SMK di Kabupaten Minahasa Tenggara berdasarkan 4 Standar Nasional Pendidikan yang berbasis Evaluasi diri sekolah dan Memperoleh model terbaik untuk memprediksi akreditasi SMA/SMK berdasarkan 4 Standar Nasional Pendidikan terhadap Akreditasi Sekolah. Sampel yang diambil adalah $11 \mathrm{SMA} / \mathrm{SMK}$ di Kabupaten Minahasa Utara. Metode yang digunakan adalah dengan analisis deskripsi dan best subset regression. Hasilnya menunjukkan bahwa berdasarkan analisis deskripsi, SMA Negeri 1 Tombatu adalah sekolah yang memiliki sarana dan prasarana yang paling baik dan SMA Negeri 2 Ratahan adalah sekolah yang paling buruk. Sementara itu, Untuk Standar pengelolaan pendidikan SMK Negeri 1 Ratahan untuk sekolah yang paling tinggi dan SMK Kristen Tombatu untuk sekolah yang paling rendah untuk standar pengelolaan pendidikan. Selanjutnya, SMK Kristen Tombatu memiliki standar pembiayaan yang lebih tinggi dan SMK Negeri 1 Posumaen adalah sekolah yang standar pembiayaan pendidikan yang lebih rendah. SMA Negeri 1 Belang memiliki standar peniliain yang sangat tinggi dan SMK Kristen Tombatu yang terendah. Berdasarkan best subset regression diperoleh hasil untuk memprediksi Akrditasi SMA/SMK di Kabupaten Minahasa Tenggara berdasarkan Standar Nasional Pendidikan terhadap akreditasi sekolah hanya diperlukan standar sarana dan prasarana, standar pembiayaan pendidikan dan standar penilaian pendidikan untuk memprediksi akreditasi sekolah tanpa mengesampingkan faktor standar pengelolaan pendidikan.
\end{abstract}

Kata kunci : Standar Nasional Pendidikan, Analisis Deskripsi, best subset regression, Kabupaten Minahasa Utara

\section{DESCRIPTION OF SMA AND SMK IN SOUTHEAST MINAHASA DISTRICT BASED ON INDICATORS OF NATIONAL STANDARDS OF EDUCATION BASED ON SCHOOL SELF EVALUATION (STANDARD OF FACILITIES AND INFRASTRUCTURE, MANAGEMENT STANDARDS, FINANCING STANDARDS AND ASSESSMENT STANDARDS)}

\begin{abstract}
National Standards of Education is an education system implemented throughout the jurisdiction of the Unitary State of the Republic of Indonesia. The purpose of this study is to describe SMA / SMK in Southeast Minahasa Regency based on 4 National Standards of Education based on school self-evaluation and Obtaining the best model to predict accreditation of SMA / SMK based on 4 National Standards of Education on School Accreditation. Samples taken are 11 SMA / SMK in North Minahasa Regency. The method used is with description analysis and best subset regression. The results showed that based on the description analysis, SMA Negeri 1 Tombatu is the school that has the best facilities and infrastructure and SMA Negeri 2 Ratahan is the worst school. Meanwhile, for the standard of management education SMK Negeri 1 Ratahan for the
\end{abstract}


highest school and SMK Kristen Tombatu for the lowest school for education management standards. Furthermore, SMK Kristen Tombatu has higher financing standards and SMK Negeri 1 Posumaen is a school with a lower standard of education finance. SMA Negeri 1 Belang has a very high standard of penicillin and the lowest Vocational Christian Tombatu. Based on the best subset regression, results obtained to predict the accreditation of SMA / SMK in South Minahasa Regency based on the National Education Standards for school accreditation only required the standard of facilities and infrastructure, education financing standards and educational assessment standards to predict accreditation of schools without compromising the standard of education management.

Keywords: National Education Standards, Analysis Description, best subset regression, North Minahasa District

\section{PENDAHULUAN}

\section{Latar Belakang}

Pendidikan nasional berfungsi untuk mengembangkan kemampuan dan membentuk watak serta peradaban bangsa yang bermartabat dalam rangka mencerdaskan kehidupan bangsa. Sedangkan tujuan pendidikan nasional adalah untuk mengembangkan potensi peserta didik agar menjadi manusia yang beriman dan bertakwa kepada Tuhan Yang Maha Esa, berakhlak mulia, sehat, berilmu, cakap, kreatif, mandiri, dan menjadi warga negara yang demokratis serta bertanggung jawab (Undang-undang nomor 20 tahun 2003 pasal 3).

Untuk mengurangi perbedaan mutu pendidikan tersebut, maka telah dibuatkan Peraturan Pemerintah (PP) nomor 19 tahun 2005 tentang Standar Nasional Pendidikan. Standar nasional pendidikan terdiri dari 8 standar, yaitu Standar Kompetensi Lulusan, Standar Isi, Standar Proses, Standar Pendidikan dan Tenaga Kependidikan, Standar Sarana dan Prasarana, Standar Pengelolaan, Standar Pembiayaan Pendidikan dan Standar Penilaian Pendidikan.

Purwanto, Hatidja, dan Paendong (2015); Sepang, Hatidja dan Langi (2015), menyatakan bahwa terdapat 2 SMA dan 2 SMK di Kabupaten MITRA mempunyai mutu yang tidak memenuhi Standar Nasional Pendidikan (SNP). Peubah yang digunakan adalah 8 SNP (Standar Kompetensi Lulusan, Standar Isi, Standar Proses, Standar Tenaga Pendidik dan Tenaga Kependidikan, Standar Sarana dan Prasarana, Standar Pengelolaan, Standar Pembiayaan Pendidikan dan Standar Penilaian Pendidikan). Namun peubah yang diukur hanya terbatas pada input (nilai siswa yang diterima), output (nilai siswa dari kelas 9 sampai dengan kelas 12), jumlah siswa, jumlah ruangan, jumlah tenaga pendidik dan tenaga kependidikan berdasarkan kualifikasi pendidikan, jumlah sarana dan prasarana sekolah serta sumber-sumber pembiayaan pendidikan.

Peubah yang digunakan belum diukur berdasarkan Evaluasi Diri Sekolah (EDS) seperti: proses pembelajaran, proses penyusunan kurikulum, karakter lulusan, interaksi guru-siswa dalam pembelajaran, prosedur dan kriteria penilaian serta perencanaan sekolah terkait peningkatan mutu.

Oleh karena itu, maka perlu dilakukan penelitian lanjutan untuk membuat profil mutu SMA/SMK di Kabupaten MITRA berdasarkan indikator SNP untuk mendeskripsikan Sekolah Menengah Atas/Sekolah Menengah Kejuruan (SMA/SMK) di Kabupaten Minahasa Tenggara yang berbasis evaluasi diri sekolah

\section{Tujuan Penelitian}

Mendeskripsikan Sekolah Menengah Atas/Sekolah Menengah Kejuruan (SMA/SMK) di Kabupaten Minahasa Tenggara berdasarkan 4 Standar Nasional Pendidikan (Standar Kompetensi Lulusan, Standar Isi, Standar Proses, Standar Pendidik dan Tenaga Kependidikan) yang berbasis Evaluasi Diri Sekolah (EDS) dan Memperoleh model terbaik untuk memprediksi akreditasi SMA/SMK berdasarkan Standar Nasional Pendidikan (Standar Sarana dan Prasarana, Standar Pengelolaan, Standar Pembiayaan Pendidikan dan Standar Penilaian Pendidikan) terhadap akreditasi sekolah.

\section{TINJAUAN PUSTAKA} Analisis Deskripsi 
Analisis multivariat lebih banyak menekankan pada metode-metode statistik yang bersifat menggambarkan dan menganalisis data-data multivariat. Cara penggambaran data tersebut sebagian besar disajikan dalam bentuk gambar atau grafik. Dengan demikian analisis multivariat sebenarnya merupakan bagian dari statistika deskripsi (Johnson and Wichern, 2005).

\section{Regresi Linier Berganda}

Analisis yang memiliki variabel bebas lebih dari satu disebut analisis regresi linier berganda. Teknik regresi linier berganda digunakan untuk mengetahui ada tidaknya pengaruh signifikan dua atau lebih variabel bebas $\left(X_{1}, X_{2}, X_{3}, \ldots \ldots . X_{n}\right)$ terhadap variabel terikat $(Y)$. Model regresi linier berganda untuk populasi dapat ditunjukkan sebagai berikut (Supranto, 2004) :

$$
Y=\beta_{0}+\beta_{1} X_{1}+\beta_{2} X_{2}+\cdots+\beta_{n} X_{n}+e
$$

\section{Uji Asumsi Klasik}

Sebelum dilakukan pengujian analisis regresi linier berganda terhadap hipotesis penelitian, maka terlebih dahulu perlu dilakukan suatu pengujian asumsi klasik atas data yang akan diolah.

Uji normalitas bertujuan untuk menguji apakah dalam model regresi, variabel pengganggu atau residual memiliki distribusi normal. Seperti diketahui bahwa uji t dan F mengasumsikan bahwa nilai residual mengikuti distribusi normal. Ada dua cara untuk mendeteksi apakah residual berdistribusi normal atau tidak yaitu dengan analisis grafik dan uji statistik. Untuk menguji apakah data berdistribusi normal atau tidak dilakukan uji statistik KolmogorovSmirnov Test. Residual berdistribusi normal jika memiliki nilai signifikansi $>0,05$ (Ghozali, 2011).

Uji heterokedastisitas bertujuan menguji apakah dalam model regresi terjadi ketidaksamaan variance dari residual satu pengamatan ke pengamatan yang lain. Ada beberapa cara yang dapat dilakukan untuk melakukan uji heteroskedastisitas, yaitu uji grafik plot, uji Park, uji Glejser, dan uji white. Untuk Grafik Plot dapat dilihat plot antara nilai prediksi variabel dependen yaitu standart predicted value (ZPRED) dengan standart residu (SRESID). Tidak terjadi heteroskedastisitas apabila tidak ada pola yang jelas, serta titik-titik menyebar di atas dan di bawah angka 0 pada sumbu $Y$ (Ghozali, 2011).

Uji multikolinieritas dilakukan untuk menguji apakah pada model regresi ditemukan adanya korelasi antar variabel bebas. Pengujian ada tidaknya gejala multikolinieritas dilakukan dengan memperhatikan nilai matriks korelasi yang dihasilkan pada saat pengolahan data serta nilai VIF (Variance Inflation factor) dan toleransinya. Tolerance mengukur variabilitas variabel bebas yang terpilih yang tidak dijelaskan oleh variabel bebas lainnya. Jadi nilai tolenrance yang tinggi sama dengan nilai VIF tinggi (karena VIF $=1 /$ Tolerance) (Nur dan Priantinah, 2012).

\section{Pemilihan Model Terbaik}

Regresi terbaik (best subset Regression) digunakan untuk meregresikan satu peubah respon pada semua kemungkinan kombinasi subset peubah-peubah prediktor dan kemudian memilih subset terbaik untuk setiap ukuran (size) informasi model terbaik ini dipilih berdasarkan nilai R-square terbesar. Pada setiap regresi subset terbaik ditampilkan statistik, yaitu : R-sq, adj R-sq, S dan C-p. Jika model difit tanpa konstanta, Rsq dan adj R-sq tidak ditampilkan (Draper dan Smith. 1992).

\begin{tabular}{rrr}
\multicolumn{2}{c}{ Kriteria-kriteria } & yang dapat \\
digunakan untuk & \multicolumn{2}{c}{ menentukan } \\
variabel/peubah-peubah & bebas yang
\end{tabular} digunakan sehingga diperoleh model terbaik untuk melakukan regresi dengan jumlah variabel yang dipilih yaitu :

1. Nilai R-Sq terbesar

2. Nilai R-Sq (Adj) terbesar

3. Nilai C-p Mallow terkecil

4. Nilai S (Simpangan Baku dari Model) terkecil

\section{METODE PENELITIAN}

Penelitian dilakukan pada bulan Mei 2016 dan tempat penelitian dilakukan di Kabupaten Minahasa Tenggara.

\section{Sumber Data dan Teknik Pengambilan Data}

Data yang digunakan dalam penelitian ini berasal dari data primer tahun 2016. Data primer diambil pada seluruh SMA dan SMK di Kabupaten Minahasa Tenggara (11 SMA/SMK). Setiap sekolah dilakukan 
wawancara terhadap 5 guru dan Kepala Sekolah Data sekunder juga diambil di Dinas Pendidikan Pemuda dan Olahraga Kabupaten Minahasa Tenggara.

\section{Objek Penelitian}

Objek penelitian yaitu 11 SMA/SMK di Kabupaten Minahasa Tenggara yaitu : SMK Negeri 1 Posumaen, SMA Negeri 1 Posumaen, SMK Negeri 1 Ratahan, SMA Negeri 1 Ratahan, SMA Negeri 1 Belang, SMA Negeri 1 Touluaan, SMA Negeri 1 Tombatu, SMK Negeri 1 Touluaan, SMK Kristen Tombatu, SMK Nasional Molompar dan SMA Negeri 2 Ratahan.

\section{Peubah Penelitian}

Peubah-peubah yang diamati adalah peubah SNP berbasis EDS yang terdiri dari Standar Sarana dan Prasarana, Standar Pengelolaan, Standar Pembiayaan Pendidikan dan Standar Penilaian Pendidikan: Peubahpeubah yang diamati disajikan pada Tabel 14.

Tabel 1. Peubah Standar Sarana dan Prasarana (X1)

\begin{tabular}{|c|l|}
\hline Kode & \multicolumn{1}{|c|}{ Nama Peubah } \\
\hline X11 & $\begin{array}{l}\text { Kondisi Kenyamanan Ruang Kerja Kepala } \\
\text { Sekolah }\end{array}$ \\
\hline X12 & $\begin{array}{l}\text { Kondisi Penggunaan Sarana laboratorium } \\
\text { Sekolah }\end{array}$ \\
\hline X13 & $\begin{array}{l}\text { Penyebab utama peralatan yang rusak di } \\
\text { laboratorium }\end{array}$ \\
\hline X14 & Kondisi ruang kelas yang dimiliki disekolah \\
\hline X15 & $\begin{array}{l}\text { Kondisi laboratorium dan perlengkapan yang } \\
\text { dimiliki oleh sekolah }\end{array}$ \\
\hline X16 & Kondisi ruang kerja guru disekolah \\
\hline
\end{tabular}

Tabel 2. Peubah Standar Pengelolaan (X2)

\begin{tabular}{|c|c|}
\hline Kode & Nama Peubah \\
\hline $\mathrm{X} 21$ & $\begin{array}{l}\text { Hal yang dijadikan pertimbangan dalam } \\
\text { penyusunan visi dan misi sekolah }\end{array}$ \\
\hline $\mathrm{X} 22$ & $\begin{array}{l}\text { Ukuran kompetensi lulusan mencerminkan } \\
\text { keterwujudan visi, keterlaksanaan misi dan } \\
\text { ketercapaian tujuan sekolah }\end{array}$ \\
\hline $\mathrm{X} 23$ & $\begin{array}{l}\text { Cara penyusunan rencana kerja sekolah (baik } \\
\text { RKS maupun RKA-S) }\end{array}$ \\
\hline $\mathrm{X} 24$ & Upaya pengembangan karier guru \\
\hline $\mathrm{X} 25$ & Rencana kerja tahunan yang dimiliki sekolah \\
\hline $\mathrm{X} 26$ & Pedoman pengelolaan yang dimiliki Sekolah \\
\hline $\mathrm{X} 27$ & $\begin{array}{l}\text { Pihak-pihak yg terlibat dalam pengambilan } \\
\text { keputusan di sekolah }\end{array}$ \\
\hline $\mathrm{X} 28$ & $\begin{array}{l}\text { Pihak pemangku kepentingan yang dilibatkan } \\
\text { dalam pengembangan dan penetapan visi, misi, } \\
\text { dan tujuan sekolah }\end{array}$ \\
\hline $\mathrm{X} 29$ & Revisi visi/misi sekolah pada tahun terakhir \\
\hline $\mathrm{X} 210$ & Penyusunan program peningkatan mutu sekolah \\
\hline $\mathrm{X} 211$ & $\begin{array}{l}\text { Program pengawasan dan evaluasi yang disusun } \\
\text { dan dilakukan di sekolah }\end{array}$ \\
\hline $\mathrm{X} 212$ & $\begin{array}{l}\text { Evaluasi program pengawasan pelaksanaan } \\
\text { akademik internal sekolah yang telah dilakukan }\end{array}$ \\
\hline
\end{tabular}

\begin{tabular}{|c|c|}
\hline $\mathrm{X} 213$ & $\begin{array}{l}\text { Tindak lanjut kepala sekolah terhadap hasil } \\
\text { temuan supervisi }\end{array}$ \\
\hline $\mathrm{X} 214$ & $\begin{array}{l}\text { Evaluasi pendayagunaan pendidik dan tenaga } \\
\text { kependidikan di sekolah }\end{array}$ \\
\hline $\mathrm{X} 215$ & $\begin{array}{l}\text { Program peningkatan mutu sekolah pada tahun } \\
\text { ini }\end{array}$ \\
\hline $\mathrm{X} 216$ & $\begin{array}{llll}\begin{array}{l}\text { Mekanisme } \\
\text { sekolah }\end{array} & \text { penetapan } & \text { struktur } & \text { organisasi } \\
\end{array}$ \\
\hline $\mathrm{X} 217$ & $\begin{array}{l}\text { Hal yang dijadikan pertimbangan sekolah dalam } \\
\text { memberikan tugas pada PTK }\end{array}$ \\
\hline $\mathrm{X} 218$ & $\begin{array}{l}\text { Mekanisme yang dilalui } \\
\text { pelaksanaan kegiatan disekolah }\end{array}$ \\
\hline $\mathrm{X} 219$ & $\begin{array}{l}\text { Prinsip-prinsip yang telah diterapkan dalam } \\
\text { seleksi penerimaan peserta didik baru }\end{array}$ \\
\hline $\mathrm{X} 220$ & $\begin{array}{l}\text { Kebijakan dan program apa saja yang telah } \\
\text { dikembangkan dan diterapkan oleh sekolah } \\
\text { dalam upaya pembinaan karakter dan disiplin } \\
\text { siswa }\end{array}$ \\
\hline $\mathrm{X} 221$ & $\begin{array}{l}\text { Kebijakan pimpinan sekolah dalam peningkatan } \\
\text { kualitas pembelajaran dan mutu pendidikan di } \\
\text { sekolah }\end{array}$ \\
\hline $\mathrm{X} 222$ & $\begin{array}{llll}\begin{array}{l}\text { Media sosialisasi } \\
\text { diterima guru }\end{array} & \text { visi/misi } & \text { sekolah yang } \\
\end{array}$ \\
\hline $\mathrm{X} 223$ & $\begin{array}{l}\text { Pihak-pihak yang terlibat dalam pengambilan } \\
\text { keputusan di sekolah }\end{array}$ \\
\hline $\mathrm{X} 224$ & $\begin{array}{l}\text { Kepala sekolah dan guru berinteraksi/bekerja } \\
\text { sama dalam pelaksanaan program sekolah }\end{array}$ \\
\hline $\mathrm{X} 225$ & Pemberlakuan Pengelolaan sekolah \\
\hline $\mathrm{X} 226$ & $\begin{array}{l}\text { Nilai-nilai budaya yang tampak dalam } \\
\text { keseharian di sekolah yang mendorong prestasi } \\
\text { peserta didik dan kinerja guru }\end{array}$ \\
\hline $\mathrm{X} 227$ & $\begin{array}{l}\text { Hal-hal yang menjadikan kepala sekolah } \\
\text { sebagai teladan bagi warga sekolah }\end{array}$ \\
\hline $\mathrm{X} 228$ & $\begin{array}{l}\text { Ketauladanan pimpinan sekolah yang ditemukan } \\
\text { dalam keseharian kegiatan sekolah }\end{array}$ \\
\hline $\mathrm{X} 229$ & $\begin{array}{l}\text { Guru mengakses laporan pengelolaan keuangan } \\
\text { sekolah }\end{array}$ \\
\hline
\end{tabular}

Tabel 3. Peubah Standar Pembiayaan Pendidikan (X3)

\begin{tabular}{|c|l|}
\hline Kode & \multicolumn{1}{|c|}{ Nama Peubah } \\
\hline X31 & $\begin{array}{l}\text { Keterlibatan orang tua siswa dalam penyusunan } \\
\text { RKAS }\end{array}$ \\
\hline X32 & $\begin{array}{l}\text { Bentuk Bantuan yang diberikan bagi peserta } \\
\text { didik miskin }\end{array}$ \\
\hline X33 & $\begin{array}{l}\text { Sarana prasarana milik sekolah yang telah } \\
\text { dihitung nilai asetnya pada tahun terakhir }\end{array}$ \\
\hline X34 & $\begin{array}{l}\text { Dokumentasi Laporan pembiayaan yang } \\
\text { dimiliki sekolah }\end{array}$ \\
\hline X35 & \begin{tabular}{l} 
Biaya investasi satuan pendidikan \\
\hline X36
\end{tabular} Biaya operasi satuan pendidikan \\
\hline X37 & Biaya personal \\
\hline
\end{tabular}

Tabel 4. Peubah Standar Penilaian Pendidikan (X4)

\begin{tabular}{|c|c|}
\hline Kode & Nama Peubah \\
\hline $\mathrm{X} 41$ & Rancangan penilaian Guru disekolah \\
\hline $\mathrm{X} 42$ & Penyelenggarakan rapat dewan pendidik \\
\hline $\mathrm{X} 43$ & $\begin{array}{l}\text { Langkah-langkah Kepala Sekolah untuk } \\
\text { menjamin kesahihan instrumen penilaian guru }\end{array}$ \\
\hline $\mathrm{X} 44$ & $\begin{array}{l}\text { Penyampaian laporan hasil evaluasi mata } \\
\text { pelajaran serta hasil penilaian setiap peserta } \\
\text { didik yang disampaikan kepada kepala sekolah }\end{array}$ \\
\hline $\mathrm{X} 45$ & $\begin{array}{l}\text { Laporan yang disampaikan kepala sekolah } \\
\text { kepada orang tua peserta didik dan kepada dinas } \\
\text { pendidikan kabupaten/kota pada setiap akhir } \\
\text { semester }\end{array}$ \\
\hline $\mathrm{X} 46$ & $\begin{array}{l}\text { Evaluasi Guru Setelah melakukan penilaian } \\
\text { hasil belajar }\end{array}$ \\
\hline $\mathrm{X} 47$ & $\begin{array}{l}\text { Kegiatan yang dilakukan sekolah terkait dengan } \\
\text { hasil ujian nasional (UN) dan ada buktinya di } \\
\text { sekolah }\end{array}$ \\
\hline $\mathrm{X} 48$ & Prinsip-prinsip penilaian yang diterapkan Guru \\
\hline
\end{tabular}




\begin{tabular}{|c|l|}
\hline X49 & $\begin{array}{l}\text { Langkah-langkah yang dilakukan guru dalam } \\
\text { menyusun instrumen penilaian }\end{array}$ \\
\hline X410 & $\begin{array}{l}\text { Bentuk ketersediaan prosedur kriteria penilaian } \\
\text { yang dapat di akses }\end{array}$ \\
\hline X411 & $\begin{array}{l}\text { Petunjuk pelaksanaan penilaian yang tersedia } \\
\text { dan digunakan disekolah }\end{array}$ \\
\hline X412 & $\begin{array}{l}\text { Teknik penilaian yang dilakukan untuk menilai } \\
\text { pengetahuan peserta didik dan dapat ditunjukkan } \\
\text { bukti fisiknya }\end{array}$ \\
\hline X413 & $\begin{array}{l}\text { Penilaian karakter peserta didik (jujur, disiplin, } \\
\text { menghargai orang lain dan bertanggung jawab) }\end{array}$ \\
\hline X414 & $\begin{array}{l}\text { Penilaian sikap perilaku yang telah guru lakukan } \\
\text { dan dapat ditunjukkan dalam bentuk fortofolio } \\
\text { peserta didik dalam satu semester }\end{array}$ \\
\hline X415 & $\begin{array}{l}\text { Penilain Guru terhadap kompetensi peserta didik } \\
\text { dalam berkomunikasi efektif dan santun }\end{array}$ \\
\hline X416 & $\begin{array}{l}\text { Penilain Guru terhadap kreatifitas peserta didik } \\
\text { dalam menyelesaikan permasalahan atau } \\
\text { menghasilkan karya }\end{array}$ \\
\hline X417 & $\begin{array}{l}\text { Penilaian keterampilan yang telah guru lakukan } \\
\text { dan dapat ditunjukkan dalam bentuk fortofolio } \\
\text { peserta didik dalam satu semester }\end{array}$ \\
\hline X418 & Manfaat dari hasil penelitian guru \\
\hline
\end{tabular}

\section{Metode Analisis}

Metode analisis yang dilakukan dalam penelitian ini ada 2 tahap. Tahap pertama, analisis deskripsi terhadap data asal. Hal ini dilakukan untuk mengetahui gambaran data secara umum. Dalam hal ini, 4 indikator SNP sebagai variabel/peubah dan SMA/SMK sebagai objek pengamatan. Tahap kedua melakukan analisis best subset regresion agar memperoleh model terbaik untuk memprediksi akreditasi SMA/SMK dengan variabel terikat $(\mathrm{Y})$ adalah Akreditasi Sekolah dan Varibel Bebas (Xi) adalah Standar Nasional Pendidikan (Standar Sarana dan Prasarana, Standar Pengelolaan, Standar Pembiayaan Pendidikan dan Standar Penilaian Pendidikan).

Tabel 5. Akreditasi SMA/SMK yang menjadi objek penelitian

\begin{tabular}{|c|l|c|}
\hline No. & \multicolumn{1}{|c|}{ Objek Penelitian } & Akreditasi \\
\hline 1. & SMK Negeri 1 Posumaen & B -75 \\
\hline 2. & SMA Negeri 1 Posumaen & B -79 \\
\hline 3. & SMK Negeri 1 Ratahan & A -86 \\
\hline 4. & SMA Negeri 1 Ratahan & A -88 \\
\hline 5. & SMA Negeri 1 Belang & B -72 \\
\hline 6. & SMA Negeri 1 Touluaan & A -88 \\
\hline 7. & SMA Negeri 1 Tombatu & B -85 \\
\hline 8. & SMK Negeri 1 Touluaan & B -81.5 \\
\hline 9. & SMK Kristen Tombatu & B -82 \\
\hline 10. & SMK Nasional Molompar & B -81 \\
\hline 11. & SMA Negeri 2 Ratahan & B -76 \\
\hline
\end{tabular}

\section{HASIL DAN PEMBAHASAN}

Dengan menggunakan program Microsoft Office Excel 2010. Maka diperoleh tampilan-tampilan grafik deskripsi masingmasing peubah seperti yang ditampilkan dibawah ini.

\section{Deskripsi Standar Sarana dan Prasarana (X1)}

Dari ke-11 sekolah yang menjadi sampel, SMA N 1 Tombatu (K7) adalah sekolah yang memiliki sarana dan prasarana yang paling baik dibandingkan sekolah lainnya di Kabupaten Minahasa Tenggara dengan memilki nilai tertinggi yaitu 20. SMK N 1 Ratahan (K3) dan SMK N 1 Touluaan (K8) adalah sekolah yang memilki nilai tertinggi kedua dengan nilai 19,4 dan SMK Kristen Tombatu (K9) memili nilai nilai 17,6 berada pada urutan sekolah tertinggi ketiga untuk standar sarana dan prasarana sekolah. SMK N 1 Posumaen (K1), SMA N 1 Ratahan (K4) dan SMA N 1 Touluaan (K6) adalah sekolah yang masih terlihat baik dalam standar sarana dan prasarana dengan nilai 15,8 diikuti SMA N 1 Posumaen (K2) dengan nilai 15,2. Dari gambar 9 menunjukkan bahwa SMK Nasional Molompar (K10) dan SMAN 1 Belang (K5) memiliki nilai yang cukup rendah dengan hanya memiliki nilai 12,6 dan 12. Dan untuk sekolah yang memiliki nilai paling rendah diantara sekolah lainnya di Kab. Minahasa Tenggara adalah SMA N 2 Ratahan (K11) dengan hanya memiliki nilai 8,4 .

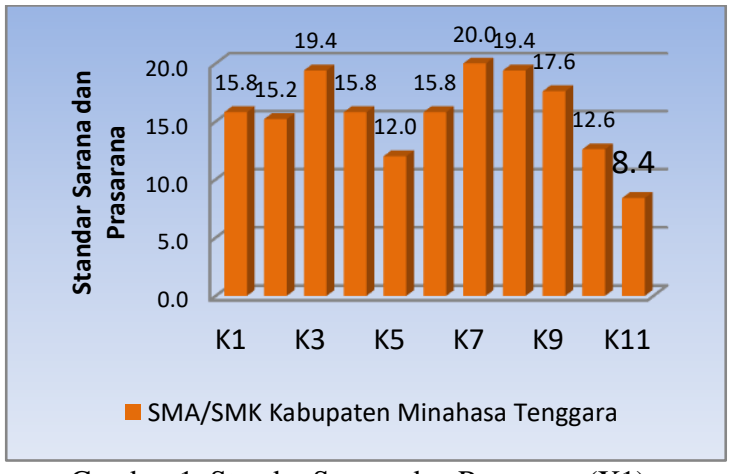

Gambar 1. Standar Sarana dan Prasarana (X1)

\section{Deskripsi Standar Pengelolaan (X2)}

Dari data yang di peroleh dan di tunjukkan di dalam gambar 2, terlihat bahwa sekolah yang ada di Kabupaten Minahasa Tenggara memiliki pengelolaan pendidikan 
yang hampir sama. Grafik menunjukkan SMK N 1 Ratahan (K3) memiliki nilai tertinggi sebesar 205,6 diikuti oleh SMA N 1 Posumaen (K2) dengan nilai 199,1 dan SMK $\mathrm{N} 1$ Touluaan (K8) yang memiliki nilai 198,4. Sementara itu, SMK N 1 Posumaen (K1) dan SMAN 1 Ratahan (K4) memiliki nilai yang sama yaitu 195,7. Masih memiliki nilai tinggi, SMK Nasional Molompar (K10) dan SMA N 1 Touluaan (K6) berada di urutan berikutnya dengan nilai 193,3 dan 190,8. SMA N 1 Belang (K5) dan SMA N 2 Ratahan (K11) adalah sekolah yang memiliki nilai yang tinggi walau berada pada urutan sekolah yang memiliki nilai yang lebih rendah dari sekolah lainnya dengan nilai 184,2 dan 177. Dan untuk sekolah yang memiliki nilai terendah adalah SMA N 1 Tombatu (K7) dan SMK Kristen Tombatu (K9) dengan hanya memiliki nilai 165,2 dan 162,8 .

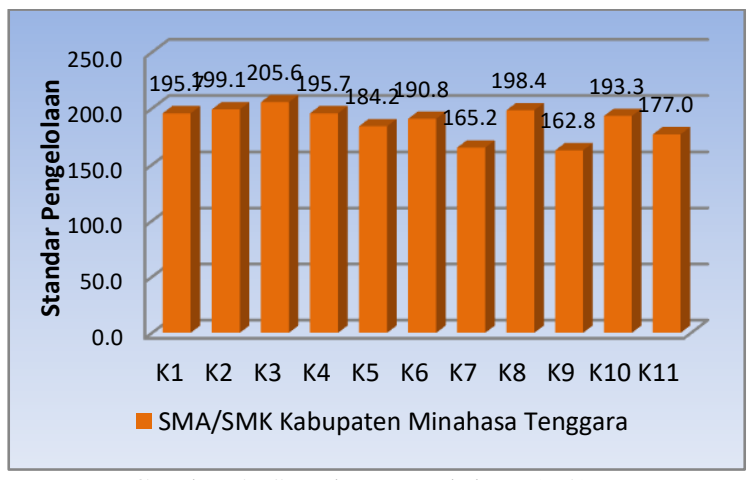

Gambar 2. Standar Pengelolaan (X2)

\section{Deskripsi Standar Pembiayaan (X3)}

Dari gambar 3 menunjukkan SMK Kristen Tombatu (K9) memiliki nilai tertinggi dengan nilai 84,3. Diurutan kedua adalah SMK N 1 Touluaan (K8) yang nilainya adalah 72,6 dan diikuti oleh SMA N 1 Posumaen (K2) dengan nilai 70,8 yang berada pada urutan ketiga. Selanjutnya SMA $\mathrm{N} 1$ Touluaan (K6) dan SMA N 1 Belang (K5) yang memiliki nilai 65 dan 62,5 berada diurutan keempat dan kelima. Memiliki nilai yang sama SMK Nasional Molompar (K10) dan SMA N 2 Ratahan (K11) berada pada urutan keenam dengan nilai 60,3. Standar pembiayaan yang cukup tinggi juga, masih di terapkan oleh SMA N 1 Tombatu (K7) dan SMK N 1 Ratahan (K3) dengan memiliki nilai 58,2 dan 52,2. Sementara untuk SMA N 1 Belang (K5) dan SMK N 1 Posumaen (K1) adalah kedua sekolah yang standar pembiayaan pendidikan yang lebih rendah di bandingkan dengan SMA/SMK lainnya di Kabupaten Minahasa Tenggara dengan hanya memiliki nilai 44,1 dan 39,1.

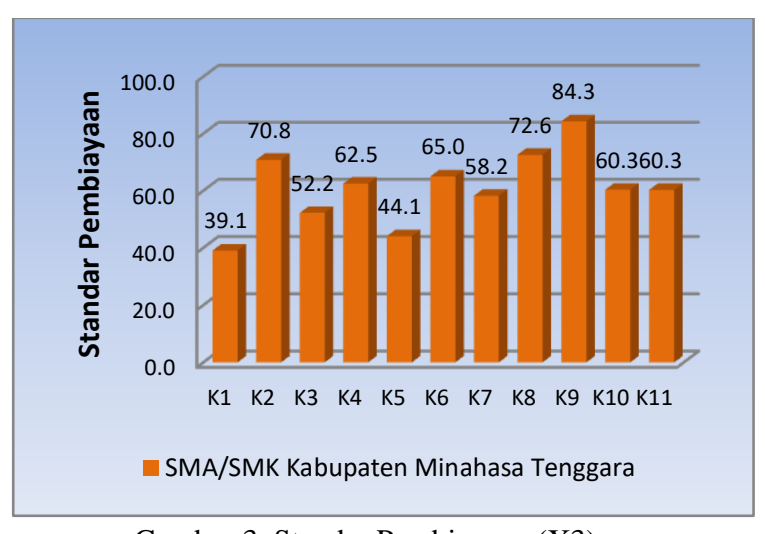

Gambar 3. Standar Pembiayaan (X3)

\section{Deskripsi Standar Penilaian (X4).}

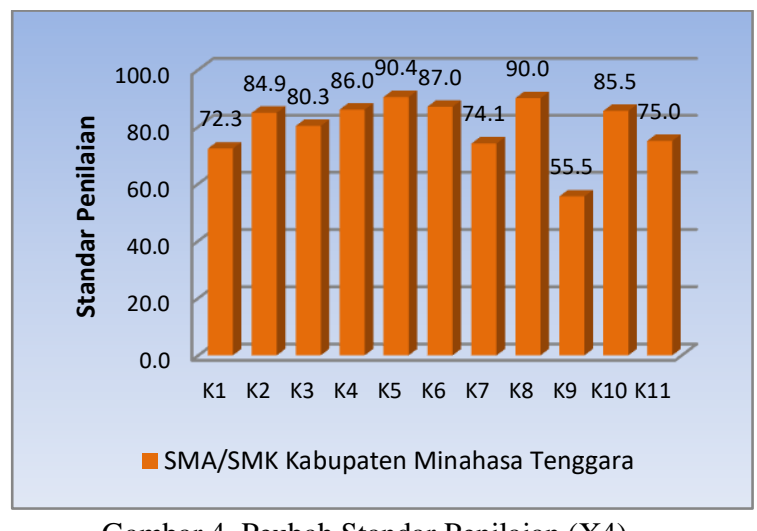

Gambar 4. Peubah Standar Penilaian (X4)

Dari grafik 4 dapat dilihat SMA N 1 Belang (K5) dan SMK N 1 Touluaan (K8) memiliki nilai yang paling tinggi yaitu 90,4 dan 90 serta sekolah yang memiliki standar penilaian paling rendah yaitu SMK Kristen Tombatu (K9) dengan nilai 55,5. Untuk sekolah yang memilki nilai diantara 80 sampai 87 ada 5 sekolah yaitu SMA N 1 Posumaen (K2), SMK N 1 Ratahan (3), SMA N 1 Ratahan (K4), SMA N 1 Touluaan (K6) dan SMK Nasional Molompar (K10). Sedangkan untuk SMK N 1 Posumaen (K1), SMA N 1 Tombatu (K7), SMA N 2 Ratahan (K11) memiliki nilai dari 72,3 sampai 75 .

\section{Normalitas Residual}

Hipotesis yang melandasi pengujian normalitas residual adalah : H0 : Residual/Error berdistribusi Normal H1 : Residual/Error tidak berdistribusi Normal 
Adapun kriteria pengujinya adalah sebagai berikut :

Jika P-Value $>\alpha$ maka Hipotesis nol diterima artinya data berdistribusi normal

Jika P-Value $<\alpha$ maka Hipotesis nol ditolak artinya data tidak berdistribusi normal

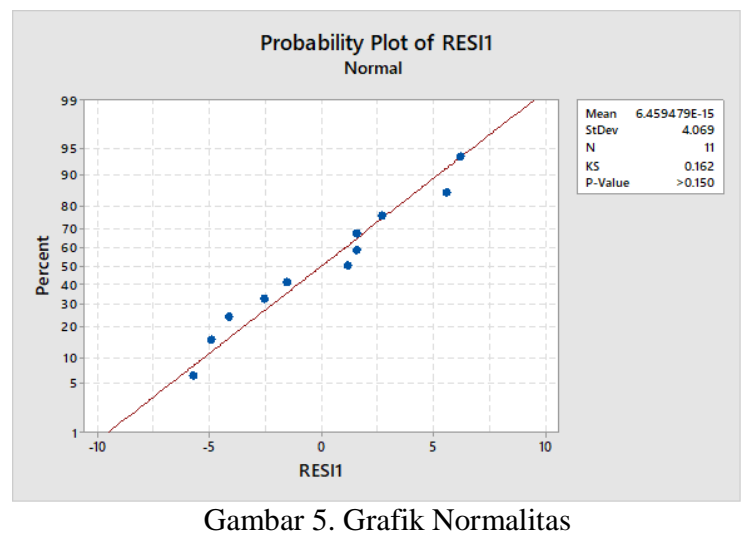

Dari gambar 5, diketahui P-value = 0,150 dengan $\alpha=0,05$ berdasarkan kriteria pengujian, maka dapat disimpulkan bahwa data berdistribusi normal karena $\mathrm{P}$-value = 0,150 lebih besar dari $\alpha=0,05$.

\section{Heteroskedastisitas}

Untuk Gejala Heteroskedastisitas dapat ditentukan dengan Uji Glejser dengan cara meregresikan antara variabel independen dengan nilai absolut residualnya dan melihat pola titik-titik pada scatterplot regeresi.

Hipotesis yang melandasi pengujian heteroskedastisitas adalah :

- $\mathrm{H}_{0}$ : Tidak ada gejala heteroskedastisitas

- $\mathrm{H}_{1}$ : Ada gejala heteroskedastisitas

Dasar pengambilan keputusan yaitu :

- $\mathrm{H}_{0}$ diterima bila signifikansi $>\alpha=0,05$ yang berarti tidak ada gejala heteroskedastisitas

- $\mathrm{H}_{0}$ ditolak bila signifikansi $<\alpha=0,05$ yang berarti ada gejala heteroskedastisitas Coefficients $^{\mathrm{a}}$

\begin{tabular}{|c|c|c|c|c|c|c|}
\hline \multirow{2}{*}{\multicolumn{2}{|c|}{ Model }} & \multicolumn{2}{|c|}{$\begin{array}{l}\text { Unstandardized } \\
\text { Coefficients }\end{array}$} & \multirow{2}{*}{$\begin{array}{c}\text { Stan } \\
\text { dardi } \\
\text { zed } \\
\text { Coeff } \\
\text { icient } \\
\text { s } \\
\text { Beta }\end{array}$} & \multirow[t]{2}{*}{$\mathrm{t}$} & \multirow[t]{2}{*}{ Sig. } \\
\hline & & $B$ & $\begin{array}{l}\text { Std. } \\
\text { Error }\end{array}$ & & & \\
\hline 1 & $\begin{array}{l}\text { (Co } \\
\text { nsta } \\
\text { nt) }\end{array}$ & -12.922 & 8.079 & & $1 . \overline{599}$ & .161 \\
\hline & $\mathrm{X} 1$ & .116 & .150 & .215 & .777 & .467 \\
\hline & $\mathrm{X} 2$ & .006 & .050 & .043 & .119 & .909 \\
\hline & X3 & .033 & .042 & .221 & .787 & .461 \\
\hline & X4 & .142 & .067 & .762 & 2.125 & .078 \\
\hline
\end{tabular}

Dari output diatas diketahui nilai signifikansi keempat varibel bebas lebih besar dari $\alpha=0,05$. Dengan demikian $\mathrm{H}_{0}$ diterima yang berarti bahwa tidak ada gejala heteroskedastisitas.

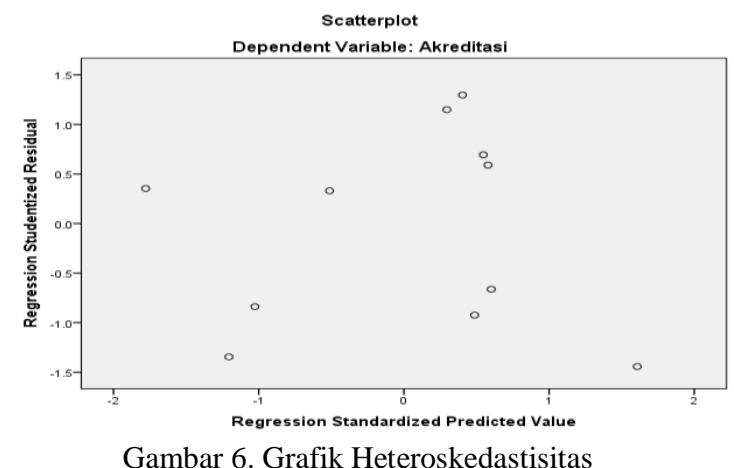

Dari pola titik-titik pada scatterplot, dapat disimpulkan tidak ada gejala Hetereroskedastisitas apabila plot menyebar merata di atas dan di bawah sumbu 0 tanpa membentuk sebuah pola tertentu.

\section{Multikolinearitas}

Untuk Mendeteksi adanya gelaja multikolinearitas dapat dilihat VIF pada gambar output di bawah. Dikatakan bahwa tidak ada gejala multikolinearitas apabila VIF $<6,5$. Dari output dibawah ini, terlihat bahwa VIF memiliki nilai $1,14,1,96,1,18$, dan 1,92 di mana kurang dari 6,5, maka tidak ada gejala multikolinearitas.

\section{Coefficients $^{a}$}

\begin{tabular}{|l|l|r|r|}
\hline \multicolumn{2}{|l|}{ Model } & \multicolumn{2}{c|}{ Collinearity Statistics } \\
\cline { 3 - 4 } & Tolerance & VIF \\
\hline 1 & $\mathrm{X} 1$ & .876 & 1.142 \\
\cline { 2 - 4 } & $\mathrm{X} 2$ & .510 & 1.961 \\
\cline { 2 - 4 } & $\mathrm{X} 3$ & .850 & 1.177 \\
\cline { 2 - 4 } & $\mathrm{X} 4$ & .522 & 1.917 \\
\hline \multicolumn{2}{|c}{} \\
\multicolumn{2}{|c}{ a. Dependent Variable: Akreditasi }
\end{tabular}

\section{Analisis Regresi Linear Berganda}

Dari data yang diperoleh akan diregresikan menggunakan sofware matematika yaitu dengan melakukan analisis regresi berganda, dan menghasilkan model regresi sebagai berikut:

$\mathrm{Y}=48,9+0,796 \mathrm{X} 1+0,016 \mathrm{X} 2+0,149 \mathrm{X} 3+0,100$ $\mathrm{X} 4$

Dari Hasil yang didapat, dilakukan pengujian serentak untuk semua variabel independen (X1, X2, X3, X4) terhadap variabel dependen (Y) dengan Uji F. Uji ini dilakukan dengan membandingkan $F_{\text {hitung }}$ dan 
$\mathrm{F}_{\text {tabel }}$ dengan $\alpha=5 \%$ (tingkat kepercayaan 95\%). adalah:

Hipotesis yang melandasi pengujian ini

- $\mathrm{H}_{0}$ : Tidak ada pengaruh standar nasional pendidikan dengan akreditasi sekolah

- $\mathrm{H}_{1}$ : Ada pengaruh standar nasional pendidikan dengan akreditasi sekolah

Adapun kriteria pengujiannya adalah sebagai berikut :

- Jika $F_{\text {hitung }}<F_{\text {tabel }}$ maka Hipotesis nol diterima artinya tidak ada pengaruh standar nasional pendidikan dengan akreditasi sekolah

- Jika $F_{\text {hitung }}>F_{\text {tabel }}$ maka Hipotesis nol ditolak artinya ada pengaruh standar nasional pendidikan dengan akreditasi sekolah

Analysis of Variance

$\begin{array}{lcccc}\text { Source } & \text { DF } & \text { Adj SS } & \text { Adj MS } & \text { F-Value } \\ \text { Regression } & 4 & 134.599 & 33.6498 & 1.22 \\ \text { X1 } & 1 & 70.099 & 70.0993 & 2.54 \\ \text { X2 } & 1 & 0.244 & 0.2438 & 0.01 \\ \text { X3 } & 1 & 30.981 & 30.9815 & 1.12 \\ \text { X4 } & 1 & 5.522 & 5.5220 & 0.20 \\ \text { Error } & 6 & 165.537 & 27.5895 & \\ \text { Total } & 10 & 300.136 & & \end{array}$

Berdasarkan kriteria dan output hasil regresi linear berganda, maka dapat disimpulkan adalah terima $\mathrm{H}_{0}$ karena $\mathrm{F}_{\text {hitung }}<$ $\mathrm{F}_{\text {tabel }}$ yaitu $1,22<4,76 . \mathrm{F}_{\text {tabel }}$ di dapat dari derajat bebas pembilang $(\mathrm{N} 1)=\mathrm{k}-1=4-1$ $=3$ dan dari derajat bebas penyebut $(\mathrm{N} 2)=\mathrm{n}$ $-\mathrm{k}=10-4=6$. Yang berarti X1, X2, X3, X4 tidak mempengaruhi $\mathrm{Y}$ atau dengan kata lain Standar Sarana dan Prasarana (X1), Standar Pengelolaan (X2), Standar Pembiayaan (X3), dan Standar Penilaian (X4) tidak mempengaruhi Akreditasi Sekolah.

\section{Pemilihan Model Terbaik}

Berdasarkan output hasil dari best subset regression, terdapat 7 persamaan sehingga dapat dibandingkan persamaan manakah yang memiliki 4 kriteria yaitu Nilai $\mathrm{R}-\mathrm{Sq}$ terbesar, Nilai R-Sq (Adj) terbesar, Nilai C-p mallow terkecil dan Nilai $S$ terkecil.

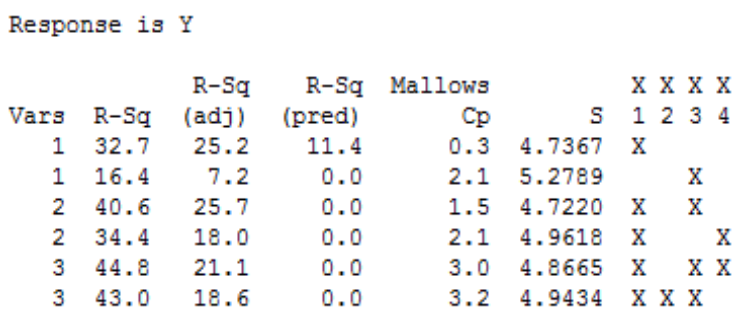

Output diatas menunjukkan ada satu persamaan yang mendekati keempat kriteria tersebut dengan R-Sq (Adj) sebesar $(21,1), \mathrm{C}$ p Mallow $(3,0)$ dan nilai $S$ terkecil $(4,8665)$ pada peubah X1, X3 dan X4. Selanjutnya dilakukan analisis regresi dengan tiga peubah tersebut, maka diperoleh hasil sebagai berikut

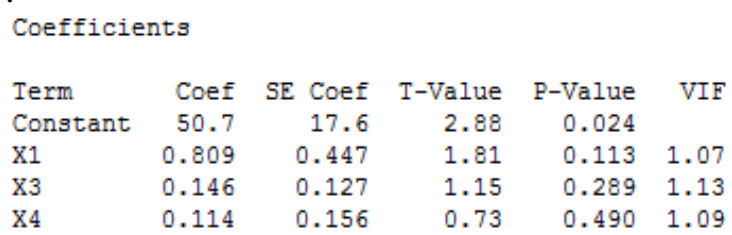

Dari hasil Output best subset regression dan analisis regresi, dapat disimpulkan model persamaan regresi terbaiknya yaitu :

$\mathrm{Y}=50,7+0,809 \mathrm{X} 1+0,146 \mathrm{X} 3+0,114 \mathrm{X} 4$

\section{KESIMPULAN}

Berdasarkan hasil dan pembahasan dapat diambil beberapa kesimpulan tentang penelitian ini yaitu:

1. Dari semua sekolah yang menjadi sampel, untuk standar sarana dan prasarana terlihat bahwa SMA N 1 Tombatu (K7) adalah sekolah yang memiliki sarana dan prasarana yang paling baik dibandingkan sekolah lainnya di Kabupaten Minahasa Tenggara. SMA N 2 Ratahan (K11) adalah sekolah yang paling buruk standar sarana dan prasarananya. Sementara itu, sekolah-sekolah yang ada di Kabupaten Minahasa Tenggara memiliki pengelolaan pendidikan yang hampir sama ini terlihat dari nilai yang selalu berdekatan dengan perbandingan SMK N 1 Ratahan (K3) untuk sekolah yang paling tinggi dan SMK Kristen Tombatu (K9) untuk sekolah yang paling rendah untuk standar pengelolaan pendidikan. Untuk standar pembiayaan, SMK Kristen Tombatu (K9) memiliki standar pembiayaan yang lebih tinggi di bandingkan SMA/SMK lain di Kabupaten Minahasa Tenggara dan SMK N 1 Posumaen (K1) sekolah yang standar 
pembiayaan pendidikan yang lebih rendah di bandingkan dengan SMA/SMK lainnya. SMAN 1 Belang (K5) memiliki standar peniliain yang sangat tinggi unggul dalam penerapan penilaian yang objektif, terpadu,ekonomis transparan, akuntabel dan edukatif serta sekolah yang memiliki standar penilaian paling rendah yaitu SMK Kristen Tombatu (K9).

2. Model regresi terbaik untuk memprediksi akreditasi SMA/SMK di Kabupaten Minahasa Tenggara adalah: $\mathrm{Y}=50,7+$ $0,809 \mathrm{X} 1+0,146 \mathrm{X} 3+0,114 \mathrm{X} 4$

Dengan melakukan uji best subset regression untuk semua varibel $\mathrm{Xi}$ terhadap varibel terikat $\mathrm{Y}$ dan diperoleh hasil untuk memprediksi Akrditasi SMA/SMK di Kabupaten Minahasa Tenggara berdasarkan Standar Nasional Pendidikan (Standar Sarana dan Prasarana, Standar Pengelolaan Pendidikan, Standar Pembiayaan Pendidikan dan Standar Penilaian Pendidikan) terhadap akreditasi sekolah hanya diperlukan standar sarana dan prasarana (X1), standar pembiayaan pendidikan (X3) dan standar penilaian pendidikan (X4) untuk memprediksi akreditasi sekolah tanpa mengesampingkan faktor standar pengelolaan pendidikan (X2).

\section{DAFTAR PUSTAKA}

Draper, N. and Smith, H. 1992. Analisis Regresi Terapan. PT Gramedia Pustaka Utama, Jakarta.

Ghozali, I. 2011. Aplikasi Analisis Multivariat dengan program SPSS, Badan Penerbit Universitas Diponegoro, Semarang.

Hatidja, Dj. Dan Mongi, Ch. 2009. Metode Statistika I. Bahan Ajar. FMIPA Unsrat, Manado.

Johnson, R. A and D. Wichern. 2005. Applied Multivariate Statistical Analysis. Fifth Edition. Prentice Hall Inc., USA.

Nur dan Priantinah. 2012. Analisis FaktorFaktor Yang Mempengaruhi Pengungkapan Corporate Social Responsibility di Indonesia. Jurnal Nominal. 1(1) : 22-34
Peraturan Pemerintah Republik Indonesia Nomor 19 Tahun 2005 tentang Standar Nasional Pendidikan.

Purwanto, Ch., Dj. Hatidja, dan M. Paendong. 2015. Pemetaan SMA/SMK Di Kabupaten Minahasa Tenggara Berdasarkan Empat Indikator Standar Nasional Pendidikan Dengan Menggunakan Analisis Biplot. Jurnal De Cartesian 4(1).

Sepang, M.Z. Dj. Hatidja, Y. Langi. 2015. Pemetaan SMA dan SMK Berdasarkan Standar Kompetensi Lulusan, Proses, Pembiayaan Pendidikan, dan Penilaian Pendidikan Menggunakan Analisis Biplot di Kabupaten Minahasa Tenggara. Jurnal De Cartesian 4(2).

Supranto, J. 2004. Analisis Multivariat Arti dan Interpretasi. Rineka Cipta. Jakarta.

Undang-Undang Republik Indonesia Nomor 20 Tahun 2003 Tentang Sistem Pendidikan Nasional. 